\title{
GEOGRAFIA DO PODER EM GOFFMAN: VIGILÂNCIA E RESISTÊNCIA, DOMINAÇÃO E PRODUÇÃO DE SUBJETIVIDADE NO HOSPITAL PSIQUIÁTRICO**
}

\author{
GEOGRAPHY OF POWER IN GOFFMAN: SURVEILLANCE \\ AND RESISTANCE, DOMINATION AND PRODUCTION \\ OF SUBJECTIVITY AT THE PSYCHIATRY HOSPITAL
}

Sílvio José BENELLI
Abílio da COSTA-ROSA

\section{RESUMO}

Neste artigo, estamos procurando recuperar alguns estudos de Goffman, lidos a partir das discussões atuais da análise institucional, das contribuições de Michel Foucault relativas à microfísica do poder e das investigações de alguns pesquisadores quanto à produção de subjetividade nas instituições de Saúde Coletiva. Goffman, apesar de não estar munido dos recursos teóricos de tais pesquisadores, já era capaz de explicitar em suas análises muito mais do que provavelmente imaginava articular. Acreditamos que Goffman já produz acuradas cartografias do dispositivo manicomial, descrevendo toda uma geografia do poder na instituição total, atento aos detalhes da rotina cotidiana. Suas investigações da dimensão intra-institucional desses dispositivos continuam atuais e eficazes para a compreensão da produção da subjetividade no contexto institucional. Também encontramos muitas ressonâncias notáveis entre Goffman e Foucault.

Palavras-chave: análise institucional, instituição total, microfísica do poder, cartografia, produção de subjetividade.

\footnotetext{
(*) Este artigo é parte da pesquisa de mestrado: "Pescadores de Homens. A produção da subjetividade no contexto institucional de um Seminário Católico", que está sendo desenvolvida por Sílvio José Benelli, sob orientação do Prof. Dr. Abílio da Costa-Rosa, com financiamento da FAPESP.

(2) Aluno do Curso de Pós-Graduação, Mestrado em Psicologia - Faculdade de Ciências e Letras, UNESP, Assis, SP. Endereço para correspondência: Av. Tarumã, 577. Centro. Tarumã, SP, CEP 19820-000 Fone: (18) 3329-1234. E-mail: sjbewelli@yahoo.com.br

(3) Professor Assistente Doutor junto ao Departamento de Psicologia Clínica e do Curso de Pós-Graduação em Psicologia - Faculdade de Ciências e Letras, UNESP, Assis, SP.
} 


\begin{abstract}
In this article, we are looking into some Goffman's studies, lead by currently discussions of institutional analysis, Michel Foucault's contributions upon microphysics of power and some other researchers from the production of subjectivity at the Collective Health. In spite of not having those theoretical resources from the later, Goffman was already able to explain in his analysis further than he could suppose. We believe that Goffman produces accurately mappings of the psychiatry hospital devices, by describing the geography of power into the total institution, and concerned to the details of everyday life. His investigations of the intra-institutional dimension from such mechanisms are still at present and efficient for the comprehension of production of subjectivity at institutional context. Also, we have come across many remarkable echoes between Goffman's and Foucault's works.
\end{abstract}

Key words: institutional analysis, total institutional, microphysics of power, mapping, production of subjectivity.

\section{ANATOMIA POLÍTICA DO DETALHE EM GOFFMAN}

Foucault (1999b, p. 120), ao estudar a disciplina, indica que uma nova "microfísica do poder" - constituída por "técnicas sempre minuciosas, muitas vezes íntimas, importantes porque definem um certo modo de investimento político e detalhado do corpo" - emergiu no mundo moderno e espalhou-se por todo o corpo social. "A disciplina é uma anatomia política do detalhe": trata-se de "pequenas astúcias dotadas de um grande poder de difusão, arranjos sutis, de aparência inocente, mas profundamente suspeita, dispositivos que obedecem a economias inconfessáveis, ou que procuram coerções sem grandeza." Para descrever os mecanismos disciplinares, é preciso demorarse sobre os detalhes e na atenção às minúcias, buscando detectar sua coerência tática.

Acreditamos que Goffman (1987) tenha como programa justamente proceder a uma observação minuciosa do detalhe, buscando, ao mesmo tempo, um enfoque político dessas pequenas coisas do cotidiano, utilizadas para o controle, dominação e - diremos também - produção de subjetividade no contexto institucional (Costa-Rosa, 2002).
Goffman (1987), em seu artigo "A vida íntima de uma instituição pública", realiza uma perspicaz análise das práticas sociais que se produzem no contexto institucional de um hospital psiquiátrico, denominado "Hospital Central". Ao deter-se nos detalhes da organização intra-institucional do dispositivo manicomial, mapeia, cartografa com meticulosidade toda uma "geografia" do poder, detectando com precisão seus diversos deslocamentos: estratégias de dominação, de produção de subjetividade, focos de resistência, táticas de subversão do instituído e movimentos instituintes.

Para além de uma linguagem de certo modo ainda funcionalista - utilizada por Goffman (1987, p. 148), por exemplo, em expressões tais como: "a participação numa entidade social impõe compromisso e adesão", dando a entender, inicialmente, que indivíduo e instituição são duas coisas distintas - podemos perceber em suas análises, se lidas com atenção, como sujeitos e instituições se produzem mutuamente, numa completa implicação: as práticas institucionais produzem sujeitos como efeito dessas práticas, que por sua vez são tomados como alvos de manutenção delas ou se organizam como focos de resistência à ordem institucional. Podemos aprender com Goffman, como o poder, ao enformar práticas sociais que visam o corpo 
do homem, transformam-no num indivíduo e também num objeto científico, ao aprisioná-lo em uma certa "natureza" ou "identidade", fruto das relações poder/saber, caracterizando-o como louco, delinqüente, etc.

A vida no contexto institucional produz "suposições" referentes à natureza, aos modos de ser e agir dos seus diversos habitantes: costuma ser normativa e normativizante. Esses atores institucionais podem enfrentar de modo variável essa "definição de si mesmos" que a instituição produz: podem resistir abertamente "e desafiar com desfaçatez os olhares de redefinição que as pessoas lhes dirigem" (Goffman, 1987, p. 149); podem recusar veladamente esse assujeitamento; podem, finalmente, reconhecer-se nessa definição institucional do seu ser, "sendo, diante de si mesmos, aquilo que os outros participantes acham que devem ser" (Idem). Podemos destacar aqui a relevância da sutileza efetiva do poder enquanto olhar e visibilidade, que será objeto de discussão em Foucault (1982, 1984, 1999b).

\section{GOFFMAN COMO ANALISTA INSTITUCIONAL}

Goffman (1987, p. 149) se posiciona como um analista institucional, armado com os instrumentos sociológicos de que dispõe, para conceituar a instituição:

\footnotetext{
Uma 'organização formal instrumental' pode ser definida como um sistema de atividades intencionalmente coordenadas e destinadas a provocar alguns objetivos explícitos e globais. O produto esperado pode ser: artefatos materiais, serviços, decisões ou informações; pode ser distribuído entre os participantes de maneiras muito diversas. Aqui interessar-me-eiprincipalmente pelas organizações formais localizadas nos limites de um único edifício ou complexos de edifícios adjacentes, e, por comodidade, a essa unidade fechada darei o nome de estabelecimento social, instituição ou organização.
}

Podemos observar nessa definição os vários elementos que compõem nosso atual conceito de instituição: as práticas discursivas, plano lógico ou "formal" ("os objetivos explícitos e globais"); plano das práticas não-discursivas ("instrumental", "sistema de atividades intencionalmente coordenadas"); um "produto" que pode ser material ou imaterial; uma distribuição desse "produto", que para nós não se distingue da própria produção de subjetividade: por exemplo, consideramos a produção "saúde mental" como produção de subjetividade. O aspecto "fechado" do estabelecimento indica o caráter totalitário das práticas institucionais. Os termos podem não ser os mesmos, mas não é possível lermos aí a instituição enquanto dispositivo produtor de subjetividade?

Goffman (1987, p. 150) chega a notar que "as organizações sociais podem ter muitos objetivos oficiais conflitivos, cada um deles com seus partidários próprios e pode haver alguma dúvida quanto à facção que fala oficialmente em nome da organização", detectando que o funcionamento institucional expressa os movimentos diversos de um conjunto segmentar e articulado de pulsações e ações instituintes e efeitos instituídos (Costa-Rosa, 2002). Os diversos atores que emergem no contexto institucional são produtos e produtores do mesmo, movidos por pulsações e necessidades as mais diferentes.

As instituições totais, "muradas", têm como característica o fato de que "parte das obrigações do indivíduo é participar visivelmente, nos momentos adequados, da atividade da organização, o que exige uma mobilização da atenção e de esforço muscular, certa submissão do eu à atividade considerada" Goffman (1987, p. 150). Essa é uma técnica clara de produção de sujeitos, por meio de uma coerção pelo poder: "esta imersão obrigatória na atividade da organização tende a ser considerada como símbolo do compromisso e da adesão do indivíduo; além disso, indica a aceitação, pelo indivíduo, das conseqüências da participação para uma definição de sua natureza" (Idem). O 
poder que age sobre o corpo, obrigando à docilidade participativa e visível, controlável pela observação, incide na criação de uma "natureza", de um certo indivíduo tomado como objeto, diríamos.

De acordo com Goffman, as instituições sobrevivem por que são capazes de apresentar contribuições úteis para a atividade de seus participantes, para o que precisa instrumentar os meios adequados com vistas às finalidades buscadas. Já sabemos que elas sobrevivem também por vários outros motivos: produção de mais-valia e de subjetividade capitalística, reproduzindo as relações sociais dominantes (Costa-Rosa, 1987, 1995, 2000, 2002).

Uma organização pode se identificar com a equipe dirigente que a administra e esta pode "reconhecer limites de confiança para a atividade adequada de cada participante" (Goffman, 1987, p. 151): tende a considerar o homem como um ser "notoriamente fraco", portanto, tem que "aceitar soluções intermediárias", "mostrar consideração", "tomar medidas de proteção".

Podemos observar que estudos tipicamente funcionalistas sobre instituições e seus diversos atores (agentes institucionais e clientela) tendem a um raciocínio particularizante, numa perspectiva sociologizante ou psicologizante, remetendo ao sujeito individual questões que são de ordem coletiva: as relações de poder que constituem a realidade institucional tendem a ser mascaradas, os conflitos e lutas são tomados como distúrbios psíquicos do indivíduo, sendo reduzidos a problemas individuais. Trata-se mesmo de uma psicologização do político e também de uma particularização de fenômenos coletivos, numa "difusão capilar dos mecanismos de controle social na comunidade". (Rotelli, 1990).

A partir da concepção de uma fraqueza natural do objeto institucional, a lógica institucional costuma considerar que o ser humano deve ser tratado a partir de "padrões de bem-estar" superiores ao mínimo exigido para a simples sobrevivência: conforto, saúde e segurança, etc.; supõe que um participante pode cooperar quando seus objetivos coincidam ou se identifiquem com os da instituição; considera que a participação também pode ser obtida por meio de "incentivos": "prêmios ou pagamentos indiretos que francamente atraem o indivíduo como alguém cujos interesses finais não se confundem com os da organização" (Goffman, 1987, p. 152); finalmente, supõe que seja possível obter a cooperação do indivíduo por meio das "sanções negativas": "ameaças, castigos, reduções nos níveis usuais de bemestar"(Idem), etc. "O medo do castigo pode ser adequado para impedir que o indivíduo realize determinados atos, ou deixe de realizá-los; no entanto, os prêmios positivos parecem necessários para que se consiga um esforço prolongado, contínuo e pessoal." (Ibidem).

A concepção de que um homem age ou deixa de agir movido por castigos (punições) e/ou por prêmios implica uma suposição teórica de que esse objeto funciona, por exemplo, a partir do princípio do prazer e da evitação da dor. Assim se produz o saber, a partir de práticas institucionais.

A partir dessas considerações, Goffman afirma que a instituição, além de

usar a atividade de seus participantes (...), também delineia quais devem ser os padrões oficiais de bem-estar, valores conjuntos, incentivos e castigos. Tais concepções ampliam um simples contrato de participação numa definição da natureza ou do ser social do participante. (...) Portanto, nas disposições sociais de uma organização, se inclui uma concepção completa do participante - e não apenas uma concepção dele como e enquanto participante - mas, além disso, uma concepção dele como ser humano (Goffman,1987, p. 152-153).

Isso quer dizer que as instituições produzem indivíduos (objetos) e saberes, definem seus participantes num processo de objetificação. Trata-se de sujeitos "dessubjetivados" (Jorge, 1983), reduzidos a objetos materiais e teóricos 
manipuláveis por meio de certas técnicas e instrumentos. O que podemos caracterizar como o modo de produção típico das instituições numa sociedade inserida no Modo Capitalista de Produção (MCP): subjetividade serializada, capitalística (Costa-Rosa, 2000).

As instituições lidam com os indivíduos a partir da concepção que criam a respeito de suas identidades: a de serem capazes de colaborar motivados por prêmios ou castigos, independentemente de se identificarem ou não com os objetivos oficiais daquelas. Há até mesmo uma "naturalização" da possibilidade de que os indivíduos considerem corretas e aceitáveis tais suposições, a ponto de torná-las imperceptíveis, invisíveis, mas reais e efetivas. É "nos pequenos atos de vida" (Goffman, 1987, p. 153) que podemos observá-las em sua incidência. No nível microfísico, portanto (Foucault, 1999b).

Goffman (1987, p. 157) explicita claramente que as instituições não se limitam a um discurso sobre a suposta natureza do seu objeto, mas sua ação também se produz especificamente a partir do conceito que têm do participante. $\mathrm{O}$ discurso ("ideologia explícita e verbal") e a prática ("ação") exprimem uma concepção do objeto sobre o qual atuam. Por outro lado, com relação ao indivíduo, "participar de determinada atividade com o espírito esperado é aceitar que se é um determinado tipo de pessoa que vive num tipo determinado de mundo" Goffman (1987, p. 158). Ou seja, implica um determinado tipo de posicionamento subjetivo, no caso, posição de objeto de uma ação institucional.

Vemos como estratégias de poder (técnicas) mais toscas e brutais (castigos) e outras mais refinadas e sutis (prêmios) são utilizadas a partir de concepções (conceituações, teorias): relações de poder e saber se produzem mutuamente, instantaneamente (Foucault, 1999b). Goffman (1987) nos mostra como saber e poder estão imbricados num único processo que produz subjetividade. Mas Goffman, longe de qualquer ingenuidade desavisada, percebe que onde há poder, há contrapoder, há resistências, coincidindo com Foucault (1982):
Ora, se qualquer estabelecimento social pode ser considerado como um lugar onde sistematicamente surgem suposições a respeito do eu, podemos ir adiante e considerar que é um local onde tais suposições são sistematicamente enfrentadas pelo participante. Adiantar-se nas atividades prescritas, ou delas participar segundo formas não-prescritas, ou por objetivos não-prescritos, é afastar-se do eu oficial e do mundo oficialmente disponível para ele. Prescrever uma atividade é prescrever um mundo; eludir uma prescrição pode ser eludir uma identidade (Goffman, 1987, p. 158).

Assim como toda instituição inclui uma disciplina de atividade, inclui também uma "disciplina de ser" (Goffman, p. 159), uma obrigação de ser um determinado habitante de um certo mundo. Produz subjetividade, que pode até ser entendida como uma certa noção de identidade psicológica internalizada (capitalística), mas também como transubjetividade (singularizada), englobando outros elementos da realidade, remetendo ao coletivo social. Mas o indivíduo, a despeito da imagem que apresenta, pode resistir e produzir uma vida no sentido contrário e/ou diverso das forças institucionais hegemônicas.

\section{OS AJUSTAMENTOS PRIMÁRIOS E SECUNDÁRIOS: MOVIMENTOS DE ADAPTAÇÃO E RESISTÊNCIA NA INSTITUIÇÃO TOTAL}

O indivíduo que coopera com as atividades institucionais sob as condições exigidas é um colaborador: um indivíduo "normal", "programado", "interiorizado". "Em resumo, verifica que, oficialmente, não deve ser não mais e não menos do que aquilo para o que foi preparado, e é obrigado a viver num mundo que, na realidade, Ihe é afim. Isso se dá através dos ajustamentos primários (Goffman, 1987, 159) do indivíduo à instituição e desta a ele. Nós dizemos adaptação, "sobrecodificação da subjetividade", normati- 
zação, dessubjetivação: processos de mútua produção.

A possibilidade de o sujeito resistir às manobras dessubjetivantes do poder, ou de objetificação, é denominada por Goffman (1987, idem) ajustamentos secundários. Eles englobam

qualquer disposição habitual pela qual o participante de uma organização emprega meios ilícitos, ou consegue fins não-autorizados, ou ambas as coisas, de forma a escapar daquilo que a organização supõe que deve ser e obter (...) representam formas pelas quais o indivíduo se isola do papel e do eu que a instituição admite para ele.

Consideramos que os ajustamentos secundários são estratégias de resistência dos indivíduos-alvo das práticas de poder no contexto institucional. São manifestações de forças de contra-hegemonia, podendo ter um caráter propriamente disruptivo e instituinte.

Goffman (1987, p. 165) também não deixa de notar como as instituições são capazes de tolerar, "de adaptar-se a ajustamentos secundários, não apenas através da disciplina cada vez maior, mas também por legitimar seletivamente tais práticas, esperando, dessa forma, reconquistar o controle e a soberania, mesmo com a perda de parte das obrigações dos participantes." Há movimentos estratégicos de "recuperação" de ações instituintes pelo pólo instituído, que manobra a partir de concessões táticas para manter sua hegemonia (Costa-Rosa, 1987, 2002). Trata-se de uma estratégia típica das instituições sociais em geral: manter o controle sobre os participantes, ao legitimar, como primários, alguns ajustamentos secundários, nem que seja apenas de modo temporário, para depois subtraí-los novamente.

No contexto institucional de um estabelecimento específico, os ajustamentos secundários podem ser considerados como práticas relativas à vida íntima da instituição, "correspondendo ao que o submundo é para uma cidade" (Goffman, 1987, 167). Lemos aqui a referência à dimensão intra-institucional no seu plano propriamente microfísico.

Os ajustamentos primários são importantes para manter a coesão institucional, são elementos de manutenção do status quo, já que se trata de um conjunto de práticas que o pólo subordinado desenvolve ao se identificar de modo alienado com o pólo dominante. Por outro lado, os ajustamentos secundários podem ser perturbadores (implicando a saída da instituição ou sua completa subversão) ou contidos (exercitados no contexto institucional, sem pressionar na busca de mudanças radicais).

Os ajustamentos secundários expressam um conjunto próprio de interesses específicos do pólo subordinado (que podem apresentar-se de modo passivo, contido, inclusive inadvertido). Além disso, apontam também para várias práticas alternativas que algumas vezes chegam a aspirar à elaboração de uma hegemonia dos interesses subordinados, em contraposição à dominante então vigente (perturbadores da ordem vigente) (Costa-Rosa, 2000, 2002).

Goffman (1987, p. 168) limita sua análise aos ajustamentos secundários contidos, cuja finalidade é obter vantagens pessoais individuais, não necessariamente conspiratórias ou revolucionárias. Mas essas práticas são bastante semelhantes aos ajustamentos secundários perturbadores: se a microfísica do poder constitui sujeitos e saberes, teorias, técnicas disciplinares e instrumentos de trabalho, a resistência também se verifica no plano microfísico dos detalhes (Yasui, 1999, p. 201-202; Nicácio, 1994, p. 132) quase que insignificantes do cotidiano, da intimidade intra-institucional.

\section{CARTOGRAFIAS DA LIBERDADE NA INSTITUIÇÃO TOTAL}

Ao cartografar a "geografia da liberdade" (Goffman, 1987, p.191) na instituição total, Goffman nos revela os pontos de resistência, os focos de contrapoder que se produzem no contexto institucional como fenômenos de 
contraposição à ordem vigente. É toda uma tecnologia constituída por detalhes do cotidiano que (re)produzem uma subjetividade capitalística. Portanto, conhecer a engenharia institucional que os produz é importante para desmontá-la: do mesmo modo que práticas cotidianas podem reprimir, modelar, coibir, dominar e produzir uma subjetividade alienada na reprodução das relações sociais dominantes, entendemos que serão outras tantas práticas microfísicas instituintes que produzirão implicação subjetiva, autonomização do sujeito e uma subjetividade singularizada (Rotelli, 1990; Costa-Rosa, 2000).

Goffman (1987, p. 172) optou por mapear os ajustamentos secundários especificamente do pólo subordinado, do grupo dos internados de um hospital psiquiátrico. Nisso Goffman também parece intuir que o aspecto mais valioso da produção institucional é aquele que diz respeito às aspirações do pólo subordinado, portadoras de inéditas e criativas relações sociais, diferentes e inclusive contraditórias com relação às relações sociais dominantes (Costa-Rosa, 2000). Os ajustamentos secundários da equipe dirigente e dos profissionais e técnicos empregados no estabelecimento tendem a ser insignificantes e reforçadores do padrão vigente (Goffman, 1987, p. 169-172).

Goffman (1987, p. 173) parte da hipótese de que os hospitais psiquiátricos não funcionam de acordo com a "doutrina psiquiátrica" (nível do projeto, do ideário, de metas de transformação abertas ao devir), pois também constata que na prática a teoria é outra. É o que ele denomina "sistema de enfermarias" que se observa organizando o manicômio, numa defasagem evidente entre o projeto oficial e o programa (nível do plano enquanto conjunto de propostas e instrumentos de implementação) efetivamente desenvolvido: "condições muito limitadas de vida são distribuídas como prêmios ou castigos, apresentados mais ou menos na linguagem das instituições penais." É esse "esquema" (lógica) de "ações" (práticas) e de "palavras" (discursos) que a equipe dirigente utiliza para lidar com o cotidiano do estabelecimento.
Essa distância entre o projeto psiquiátrico e o programa propriamente dito fica mais clara quando localizamos o hospital psiquiátrico no contexto sócio-histórico mais amplo (Foucault, 1999a; Amarante, 1994,1998, 2000a, 2000b; Castel, 1978): o modelo hospitalocêntrico é pautado pela norma de exclusão do convívio familiar e social, cultivando uma série de procedimentos de controle que abrangem a sexualidade, o espaço de deambulação, o que é possível ou não fazer - inclusive, ser - operando basicamente por subtração. O projeto psiquiátrico pode ser entendido como parte de uma estratégia global de controle e manutenção da atual ordem social dominante (Costa-Rosa, 1987, 1999, 2000).

Já há uma percepção, em Goffman, da semelhança, talvez mesmo da identidade entre uma ordem jurídica normativa e o "ato terapêutico", relação claramente explicitada por Foucault (1999a) na "sanção normalizadora" e na consideração de que há um "microtribunal penal" em funcionamento nas diversas instituições modernas. Goffman (1987) revela a existência de um "esquema de disciplina" autoritário que estabelece um conjunto relativamente completo de meios e fins que os pacientes podem legitimamente obter (normatização), que tem como efeito tornar ilícitas toda uma série de atividades dos pacientes. É o estatuto normativo que cria o permitido e produz também toda a região das ilegalidades (Goffman, 1987, p. 231; Foucault, 1999b).

No plano microfísico (íntimo) da instituição, há fontes materiais (Goffman, 1987, p.173) empregadas nos ajustamentos secundários; substituições (Goffman, 1987, p. 173-175), nas quais os internados utilizam artefatos disponíveis de um modo diferente daquele para o qual foram previstos; e exploração do sistema (Goffman, 1987, p. 175-188), ampliando a extensão das fontes existentes de satisfação legítima, ou explorando uma rotina completa de atividade oficial para fins particulares. $\mathrm{O}$ que podemos afirmar é que se o sujeito é silenciado, ignorado, reduzido a uma "doença" pela lógica médica 
(Jorge, 1983) predominante na instituição, essas pequenas e inumeráveis práticas, nas quais ele subverte de alguma forma os diversos "materiais" disponíveis, são o testemunho de que o sujeito resiste, insiste, se insinua, produzindo o máximo de vida possível, apesar das condições ambientais bastante adversas.

Além das fontes, há locais ou regiões onde ocorrem os ajustamentos secundários. Goffman (1987, p. 191) mapeia então "a geografia da liberdade", ou os locais livres no contexto institucional. De um modo amplo, na "geografia institucional", há o espaço situado fora dos limites do estabelecimento, portanto, inacessível para os internados. Há também o "espaço da vigilância" (nada mais foucaultiano!!), área em que o paciente pode estar, ficando sujeito à autoridade e às restrições usuais do estabelecimento. Finalmente, há um terceiro tipo de espaço: espaço não-regulamentado pela autoridade usual da equipe dirigente.

As práticas visíveis de ajustamentos secundários costumam ser ativamente proibidas no hospital psiquiátrico e nas demais instituições totais. Para realizá-las, é preciso estar "longe dos olhos e dos ouvidos da equipe dirigente" (Goffman, 1987, p. 190); basta estar fora de sua linha de visão.

Mas além dessa evitação da vigilância,

os internados e a equipe dirigente tacitamente cooperavam para permitir o aparecimento de espaços físicos limitados, onde se reduziam marcantemente os níveis usuais de vigilância e restrição - espaços em que o internado podia ter livremente uma certa amplitude de atividades proibidas e, ao mesmo tempo, certo grau de segurança (Goffman, 1987, p. 190).

A equipe dirigente pode saber ou ignorar a existência de tais espaços, "mas deles se afastava ou tacitamente deixava de exercer sua autoridade ao neles entrar". Comportamento ambíguo e algo enigmático, esse "desconhecimento" tático.

Goffman (1987, p.191) adverte que esses "locais livres" podem ser encontrados em instituições cuja autoridade está concentrada num grupo completo da equipe dirigente, "e não num conjunto de pirâmides de comando". Verificamos que a "vigilância hierárquica" (Foucault, 1999b) organizada como um poder escalonado e difuso se contrapõe à existência de tais espaços de liberdade. Isso explica porque em "Vigiar e Punir" (Foucault, 1999b) não há escapatória para o sujeito, inserido numa máquina panóptica sem falhas, sem espaço para a resistência.

Esses "locais livres" do hospital eram utilizados como ambiente para atividades especificamente proibidas, para escapar da vigilância e do controle rígido da equipe dirigente e do "stress" da convivência institucional forçada e obrigatória: "aí, a pessoa podia ser ela mesma" (Goffman, 1987, p. 193). Há "locais livres" que podem ser utilizados por diversos internados, sem sentimento de posse ou de exclusividade por parte deles. Há também os "territórios de grupo" (Goffman, 1987, p. 197), "nos quais um grupo acrescentava ao seu acesso a um local livre, um direito de manter afastados todos os outros pacientes". Um terceiro tipo de lugar, o "território pessoal", "espaço onde o indivíduo cria alguns elementos de conforto, controle e direitos tácitos que não compartilha com outros pacientes, a não ser quando os convida" (Goffman, 1987, p. 200).

O "território pessoal" constitui um contínuo que pode estender-se do "ninho" ao "refúgio", locais "em que o indivíduo se sente tão protegido e satisfeito quanto isso seja possível no ambiente" (Goffman, 1987, idem). O quarto de dormir particular é o tipo básico de território pessoal: "uma vez obtido, um quarto particular poderia ser provido de objetos que dariam conforto, prazer e controle à vida do paciente" (Goffman, 1987, p. 201). Mesmo numa enfermaria coletiva, os pacientes tendem a construir um "território pessoal" e sua formação parece obedecer à "lei do mais forte", que tende a se impor sobre os demais. "Talvez o espaço mínimo que se transformava em território pessoal fosse dado pelo cobertor de um paciente" (Goffman, 1987, p. 202). 
Depois de estudar as fontes e os locais utilizados nos ajustamentos secundários, Goffman (1987, p. 203) mapeia também os recursos disponíveis. As pessoas tendem a guardar bens legitimamente possuídos, que lhes produzem gratificações e bem-estar, com os quais se identificam e, inclusive, produzem sua vida. Elas costumam ter locais especiais onde armazenam e protegem seus bens, mantendo-os longe dos demais. "(...) tais locais podem representar uma extensão do eu e de sua autonomia, tornando-se mais importante na medida em que o indivíduo perde outros 'reservatórios' de seu eu. Se uma pessoa não pode guardar nada para si mesma, e se tudo que usa pode ser também usado por outros, há possibilidade de pouca proteção quanto à contaminação por outros" (Goffman, 1987, p. 204).

De acordo com Goffman (1987, p. 24-27), o ingresso numa instituição total implica um processo de despojamento de bens, emprego, carreira, inclusive de identidade pessoal, caracterizando o que atualmente denominamos "invalidação pessoal através da tutela institucional" (Nicácio, 1994). O indivíduo é despojado de suas roupas e pertences pessoais, dinheiro, documentos, relógio de pulso, etc. "Os cosméticos necessários para que a pessoa se apresente adequadamente diante dos outros eram coletivizados e acessíveis aos pacientes apenas em certos momentos" (Goffman, 1987, p. 205). Se, por um lado, essa técnica de despojamento aumenta a agilidade e eficiência institucional, facilitando manusear um indivíduo reduzido a um corpo, também expropriado pelo saber médico (Jorge, 1983), por outro lado, o sujeito excluído aí insiste e cria invariavelmente "esconderijos" onde possa depositar seus bens, extensões de si mesmo.

Goffman (1987, p. 206-207) descreve a rica e criativa gama de "esconderijos portáteis ou fixos" que os internados criam para guardar e proteger seus bens amealhados no contexto institucional.

"Para conseguir ajustamentos secundários eficientes, é preciso criar um meio não-oficial, geralmente escondido, para levar e trazer os objetos significativos - é preciso ter um sistema de transporte" (Goffman, 1987, p. 208). Num microcosmo onde as condições de vida são extremamente limitadas e padronizadas, bens triviais e correntes da vida civil não estão à disposição dos internados e são muito desejados e valorizados. Sistemas de transporte clandestinos permitem a circulação de "corpos, artefatos ou coisas, mensagens verbais ou escritas" (Idem). O contrabando é uma estratégia de contra-hegemonia, disponibilizando bens e objetos dos quais estão privados os internados. No hospital psiquiátrico, recursos extra-oficiais costumam ser muito tolerados, de acordo com Goffman.

"Sistemas ocultos de comunicação constituem um aspecto universal das instituições totais" (Goffman, 1987, p. 210). Isso se deve também ao "silenciamento" de fato produzido pelo discurso médico (Jorge, 1983).

Alguns pacientes, segundo o autor, mantinham a tática de não receber e não apresentar comunicação de tipo explícito. Seu afastamento silencioso era uma forma de defesa contra auxiliares e outros internos inoportunos. Mas isso acabava sendo interpretado como sinal de doença mental. Para se manter tal forma de afastamento do ambiente, permanecendo no "papel" de surdos, cegos, ou loucos, tinham que desempenhar à risca o personagem, simulando desinteresse pelo que acontecia na enfermaria, sofrer abusos sem responder, privando-se de "muitas das pequenas transações da vida social diária de dar e receber" (Goffman, 1987, p. 211). Mas eles se comunicavam através de um conjunto quase que imperceptível de convenções: exploravam meios disfarçados de comunicação direta. Outros pacientes exploravam os sistemas estabelecidos de comunicação, como os telefones do estabelecimento.

Os sistemas ilícitos de transporte podem começar de modo inocente, mas uma vez construídos, tornam-se capazes de transmitir material altamente proibido ou perigoso para a instituição. Os "transportadores" são recrutados 
espontaneamente ou por meio de coação entre quaisquer pacientes que circulem normalmente pelo estabelecimento.

\section{RELAÇÕES SOCIAIS NA INSTITUIÇÃO TOTAL: REPRODUÇÃO DO PADRÃOO DOMINANTE E PRODUÇÃO DE LAÇOS SOLIDÁRIOS}

Goffman (1987, p. 214) deduz, a partir da criação de ajustamentos secundários, a construção de uma estrutura social subterrânea (nós dizemos: microfísica, plano do invisível, passível de enunciação) na instituição total: a utilização do outro pode potencializá-los. Se as práticas da equipe dirigente tendem a transformar o homem num "objeto-doença" (Amarante, 1998), o grupo dos pacientes reage, procurando criar um outro mundo dentro das condições impostas, apesar de acabarem reproduzindo muito das próprias relações de dominação às quais estão submetidos, com seus pares.

Para utilizar o outro em benefício próprio, os pacientes podem se valer de "coerção particular" (Goffman, 1987, p. 215) expressa por meio de "expropriação aberta, extorsão, técnicas de força, submissão sexual imposta". Outra forma possível é estabelecer com o outro uma relação de "intercâmbio econômico" (Goffman, 1987 , p. 216). No hospital pesquisado, o autor afirma que os pacientes, despojados do seu dinheiro, recebiam uma mesada que podiam gastar na cantina local, mas tinham dificuldade em obter bens e seu gasto era muito limitado. Mas "os pacientes criavam meios para superar tais restrições ao uso de dinheiro" (Goffman, 1987, p. 217-218), por exemplo, tentando conservar seus recursos fora do controle da equipe dirigente.

"No hospital Central, os objetos e serviços ilicitamente comprados pelos pacientes, bem como as fontes de fundos ilicitamente empregadas, eram ilegais em diferentes graus" (Goffman, 1987, p. 218): contrabando e/ou consumo de bebidas alcoólicas era altamente proibido, a prostituição, a drogadição e a usura vinham em seguida. Havia também muitos serviços "menos proibidos" que se podiam comprar: roupas lavadas e passadas, corte de cabelo, consertos de relógios, sapatos, mensageiro, etc. Alguns pacientes se tornavam vendedores exclusivos, por exemplo, de fósforos, objeto formalmente ilegal, mas cuja posse era ignorada, sendo utilizado principalmente para acender cigarros.

Lavar e encerrar carros dos funcionários do hospital era a principal fonte de renda dos pacientes, além do que era autorizada como "mesada" ou trazida por parentes visitantes. Essa atividade tornou-se uma prerrogativa legítima por parte dos pacientes, que procuravam conciliá-la com o trabalho que tinham que fazer no hospital, criando inclusive uma certa divisão de trabalho (Goffman, 1987, p. 219).

Outras formas de obter dinheiro eram: engraxar sapatos, revender produtos e materiais ganhados: presentes, cigarros, roupas, além dos jogos de azar. No hospital pesquisado por Goffman (1987, p. 222), o cigarro era o principal substituto para o dinheiro.

A posse do dinheiro significava para os pacientes a possibilidade de "pretender obter bens fora do hospital - podiam falar numa linguagem que seria compreendida fora dali, embora oficialmente não tivessem licença para falar" (Goffman, 1987, p. 219). Atualmente falamos em recuperar a contratualidade social e econômica dos pacientes (Rotelli, 1990; Nicácio, 1994; Yasui, 1999; Costa-Rosa, 2000).

A venda e inclusive a barganha, os elementos de organização social paralela, além da troca econômica, visavam claramente ao intercâmbio social, em que predominam as trocas afetivas. Trata-se do desenvolvimento de "elos de solidariedade" (Goffman, 1987, p. 226ss) entre grupos de internados, que podem fazer parte dos ajustamentos primários, mas também podem ser elementos característicos do submundo institucional. Relações pessoais de companheirismo, de interação não-sexual, 
relações de namoro heterossexual, formação de "panelinhas" foram detectadas por Goffman. "Bens rituais" eram obtidos por meio de ajustamentos secundários para trocas simbólicas e afetivas entre os pacientes (Goffman, 1987, p. 228). O cigarro era também um elemento importante desses bens rituais.

A internação numa instituição totalitária torna a informação um bem decisivo para a sobrevivência psicológica do indivíduo, por isso condições restritivas de vida tendem a criar bens para intercâmbio econômico e social. A solidariedade também se produz na transmissão de instruções dos veteranos para os novatos, o que leva a equipe dirigente a desejar manter esses grupos separados. Procura-se evitar que os ingressantes não aprendam os "truques, manhas e vícios" dos mais experientes.

Um outro tipo de relações sociais extraoficiais importante é denominado por Goffman (1987, p. 233ss) "relações de proteção". O paciente internado no hospital estava localizado numa grade constituída basicamente por dois elementos: a sua enfermaria e o "sistema de trabalho". Este inclui trabalhos de manutenção do próprio estabelecimento: faxina, serviços gerais e vários tipos de terapia.

"A teoria do hospital era que, desde que o estabelecimento atendia a todas as necessidades dos pacientes, não havia razão para que fossem pagos pelo trabalho que faziam" (Goffman, 1987, p. 233). A disposição de trabalhar gratuitamente para o hospital era considerada sinal de convalescença e o próprio trabalho era considerado terapêutico. "A regra tradicional no hospital era que a liberdade para andar pelos pátios era dada apenas aos que, com seu trabalho, pagavam por ela" (Idem). Observamos como o hospital mimetiza a realidade social mais ampla na qual está inserido. Mas os pacientes, espertamente, obtinham liberdade de circulação pelo estabelecimento por meio de um trabalho meramente simbólico!

Os membros da equipe dirigente e os diversos técnicos que trabalhavam com os pacientes desenvolviam relações de proteção com estes. A direção do hospital reforçava o sistema de proteção por intermédio da distribuição gratuita de cigarros aos funcionários, que os utilizavam como prêmios para seus grupos de pacientes. As festas institucionais ocupam um lugar importante nesse sistema (Goffman, 1987, p. 234ss).

Além do controle formal e informal que a equipe dirigente mantém sobre o grupo dos internados, Goffman (1987, p. 242-243) verifica os movimentos de contracontrole destes últimos: provocar "acidentes" para uma pessoa da equipe da administração, a rejeição maciça de um certo tipo de alimento, diminuir o ritmo de trabalho ou de produção, sabotagem de sistemas de água, luz e comunicação, "gozação coletiva". O espectro se estende destas (re)ações inofensivas até greves ou rebeliões, quando a administração ameaça globalmente o sistema clandestino em operação no estabelecimento. Percebemos que o grupo dos internados não é apenas um objeto passivo que pode ser manuseado interminavelmente ao bel-prazer da equipe dirigente. Se muitos pacientes são de fato impotentes para esboçar alguma reação, "pequenos grupos de líderes informais" são capazes de organizar astutos ajustamentos secundários.

\section{CRIAÇÃO DE "MUNDOS" ALTERNATIVOS NO CONTEXTO INSTITUCIONAL TOTALITÁRIO: MOVIMENTOS DE LIBERDADE}

Em suas conclusões, Goffman (1987, p. 246) afirma que:

Sempre que estudamos um estabelecimento social, verificamos uma discrepância com esse primeiro tema: verificamos que os participantes se recusam, de alguma forma, a aceitar a interpretação oficial do que devem dar e retirar da organização, e, além disso, quanto ao tipo de eu e de que mundo que devem aceitar para simesmos. Onde se espera entusiasmo, haverá apatia; 
onde se espera afeição, há indiferença; onde se espera freqüência, há faltas; onde se espera robustez, há algum tipo de doença; onde as tarefas devem ser realizadas, há diferentes formas de inatividade. Encontramos inúmeras histórias comuns, cada uma das quais é, a seu modo, um movimento de liberdade. Sempre que se impõem mundos, se criam submundos.

Essa constatação se torna precisa ao considerarmos uma instituição "como formação material constituída por um conjunto de saberes e práticas articulados por um discurso de tipo ideológico (lacunar). Aquilo que o discurso procura articular não são os saberes às práticas, mas sim, saberes contraditórios e práticas contraditórias entre si" (Costa-Rosa, 2000). Assim como a sociedade pode ser entendida como uma articulação de interesses divergentes, esta tende a ser a forma como se configura também cada instituição em particular. As lacunas do discurso indicam justamente as tensões oriundas da demanda social que a instituição procura metabolizar.

Quanto mais absoluta a privação, mais os bens, pequenos e ilícitos, se tornam "recursos simbólicos" de resistência contra o sistema totalitário, "refúgios para o eu", segundo Goffman (1987, p.248).

Além disso, os pacientes costumam descobrir que é possível fugir de um lugar, mesmo sem sair dele: utilizam como técnicas de resistência diversas estratégias: "atividades de evasão" (Goffman, 1987, p. 248-251), nas quais se desconectam temporariamente de si e do ambiente (diversões e passatempos em geral, cursos de línguas, de artes, esportes, bailes e festas institucionais, namoro, atividades de representação teatral, práticas religiosas, jogos de quebra-cabeças, livros de aventuras, baralhos, adaptação exagerada ao trabalho, etc.). "Os meios individuais de criação de um mundo eram notáveis" (Goffman, 1987, p. 251).

A psicoterapia individual, "privilégio raro em hospitais públicos", também acaba sendo uma forma de evasão (!), pois "o contato com o psiquiatra da equipe dirigente é tão singular", que a própria sessão é um espaço que presumivelmente permite ao paciente distanciar-se da realidade do hospital. Paradoxalmente, "ao realmente receber aquilo que a instituição diz oferecer, o doente pode conseguir afastar-se daquilo que o hospital realmente dá"(!) (Goffman, 1987, p. 252).

Goffman sugere que os ajustamentos secundários são superdeterminados, utilizados para combater e derrotar o mundo hospitalar: "tais práticas dão às pessoas mais do que aquilo que aparentar dar; independentemente do que dêem, tais práticas parecem demonstrar - pelo menos para o praticante - que ele tem individualidade e autonomia pessoal que escapam às garras da instituição" (Goffman, 1987, p. 254). São claramente estratégias que visam manipular poder ou resistir a ele.

\section{A PRODUÇÃO DA SUBJETIVIDADE NO CONTEXTO INSTITUCIONAL}

Consideramos a sociedade como um tecido formado por uma rede de instituições sociais: a "saúde pública" é uma delas. Os supostos conflitos entre sujeito e sociedade, indivíduo e grupo, sujeito e instituição, psique e ambiente são falsas dicotomias. Trata-se de falsos problemas: só há real social, coletivo, e o indivíduo é apenas um terminal de produção social. Os sujeitos são produzidos socialmente, no bojo de processos e práticas concretas, de práticas discursivas, na intersecção entre poderes e saberes.

A subjetividade (modos de ser, sentir, pensar e agir constitutivos do sujeito em determinado momento histórico) é tecida, no contexto institucional, pela rede de micropoderes que sustenta o fazer cotidiano (institucional), operando efeitos de reconhecimento/desconhecimento dessa ação concreta.

Instituição não é uma instalação material na qual se encarnam entidades poderosas. Uma 
instituição é uma prática social que se repete e se legitima enquanto se repete. As instituições implementadas em organizações e estabelecimentos não apenas realizam - quando realizam - os objetivos oficiais para os quais foram criadas, mas também produzem determinada subjetividade em seus vários atores, sujeitos são fundados no interior das práticas, sujeitos ao mesmo tempo constituídos no e constituintes do cotidiano institucional. O pensamento costuma reificar objetos e sujeitos que só existem enquanto se produzem e são produzidos dentro de determinadas práticas institucionais.

A produção de subjetividade remete fundamentalmente ao plano micropolítico, microfísico das relações instituintes e instituídas da formação no contexto institucional. Nesta perspectiva, as relações pedagógicas, terapêuticas, educativas entre a equipe dirigente e pacientes não se configuram como relações estáticas entre pólos constituídos, mas apresentam-se em permanente constituição e ordenação - plenas de vicissitudes - em constante transformação dos lugares e posições no interior das relações, numa pulverização dos lugares instituídos e instituintes.

Desse modo, não podemos conceber práticas e/ou sujeitos autônomos, pois toda prática é efetivada por relações nas quais se configuram sujeitos. Essa é a principal condição para que as instituições existam concretamente. A solidez institucional residiria nos vínculos entre os sujeitos que as fazem cotidianamente, vínculos invisíveis, microfísicos, que se plasmam em relações instituintes e instituídas no contexto institucional, podendo ser mapeadas a partir das forças e dos poderes moleculares que as permeiam.

O hospital psiquiátrico parece ter seu núcleo subjetivizante centrado numa formação disciplinar, ao mesmo tempo moral e psicológica. A ação institucional, entre reconhecimentos e desconhecimentos incide normativamente sobre as condutas. A subjetividade produzida neste contexto seria caracterizada por traços essencialmente nomatizados/normatizadores, numa relação em que dirigentes e pacientes se instituem mutuamente por meio de um jogo de forças (ativas e reativas) que visam à normatização da conduta do outro.

\section{CONCLUSÃO}

Goffman (1987) estudou detalhadamente a estrutura, a natureza e a dinâmica psicossocial das "instituições totais", e sua análise mostra-se um instrumento valioso para estudar a produção da subjetividade no contexto institucional. Quando situamos as sofisticadas e minuciosas análises de Goffman num campo mais geral da evolução da análise das instituições, campo de referências históricas que encontramos, por exemplo, na obra de Michel Foucault, então elas ganham um sentido mais pleno e o que parecia apenas implícito pode se articular claramente.

Foucault é conhecido por não citar suas fontes e, inclusive, chegou a comentar a importância do estudo das instituições asilares realizado por Goffman (Foucault, 1984, p. 110-111). Pensamos que há mais semelhanças entre "Manicômios, prisões e conventos" (publicado originalmente em 1961) e "Vigiar e Punir" (publicado originalmente em 1975) do que se poderia suspeitar à primeira vista. Isso não parece evidente, mas uma leitura atenta de ambos pode indicar pontos de contato, temas, problemas e achados comuns nos dois autores, como tentamos demonstrar. Com isso, não negamos suas diferenças e distâncias, nem as especificidades de cada obra em si mesma. Mas as ressonâncias de um livro no outro nos pareceram bastante notáveis.

Talvez pudéssemos afirmar que há mais vida no "Panopticon" do que Bentham (Foucault, 1984, 1999b, 1999c) poderia - ou gostaria de - acreditar. O projeto de controle e visibilidade total de Bentham falha, pois focos de resistência tendem a se apoderar de todo e qualquer espaço vulnerável do dispositivo institucional. "Esses são os recantos úmidos 
onde nascem os ajustamentos secundários e de onde começam a infestar o estabelecimento" (Goffman, 1987, p. 247).

Uma leitura "foucaultiana" de Goffman (1987) revela um "genealogista", pois nos permite verificar como as relações de poder/saber produzem práticas não-, discursvivas e subjetividade na instituição total. Com Goffman, aprendemos que o manicômio possui estrutura física e simbólica, em que poderes e saberes se produzem, gerando modelos profissionais e um clima cultural específico. Desmontá-lo implica a invenção de novas instituições, partindo da ruptura epistemológica produzida pela instituição negada: a desinstitucionalização exige a elaboração de um novo paradigma (Nicácio, 1994; Costa-Rosa, 2000).

Novas instituições exigem, para sua criação, um exercício cotidiano de elaboração contínua de um projeto a partir da reflexão permanente sobre as práticas, num esforço de transformar a lógica e ação asilares. Nesse trabalho, Goffman (1987) tem uma grande contribuição a nos oferecer.

A "experiência italiana" na área da Saúde Coletiva propõe a superação do tratamento baseado na internação psiquiátrica. Sua proposta é um projeto de desmonte, peça a peça, da máquina kafkianaque Goffman (1987) nos revelou. Rotelli, apontando para a questão central, afirma que o objetivo prioritário da desinstitucionalização é transformar as relações de poder entre instituição e sujeitos e, em primeiro lugar, os pacientes:

Inicialmente, isto é, no trabalho de desconstrução do manicômio, esta transformação é produzida através de gestos elementares: eliminar os meios de contenção; reestabelecer a relação do indivíduo como próprio corpo; reconstruir o direito e a capacidade de uso dos objetos pessoais; reconstruir o direito e a capacidade de palavra; eliminar a ergoterapia; abrir as portas; produzir relações, espaços e objetos de interlocução; liberar os sentimentos; reconstituir os direitos civis eliminando a coação, as tutelas jurídicas e o estatuto de periculosidade; reativar uma base de rendimentos para poder ter acesso aos intercâmbios sociais (Rotelli, 1990, p. 32).

O sujeito (singularidade desejante) está excluído e/ou silenciado pelo dispositivo institucional totalitário (e asilar), que se pauta pelo discurso médico (Jorge, 1983). Sua emergência costuma ser apreendida no registro do desvio, do patológico, da subversão da ordem instituída. Seu advento é invariavelmente interpretado como um obstáculo que emperra o funcionamento adequado e efetivo do processo institucional. Ora, por mais que se negue, descarte o sujeito, ele persiste teimosamente em aparecer e tumultuar o ambiente, resiste ao próprio alijamento da cena institucional: manifesta-se nas disfunções e falhas que acometem as práticas microfísicas no contexto do estabelecimento. Ou como diz Goffman (1987, p. 259), nas "fendas".

\section{REFERÊNCIAS BIBLIOGRÁFICAS}

AMARANTE, P. (Org.) (1994) Psiquiatria social e reforma psiquiátrica. RJ: Fiocruz.

, (Org.) (1998) Loucos pela vida - a trajetória da reforma psiquiátrica no Brasil. $2^{\mathrm{a}}$ ed. RJ: Panorama/ENSP.

, (2000a) O homem e a serpente - outras histórias para a loucura e a psiquiatria. $1^{\mathrm{a}}$ reimpressão. $\mathrm{RJ}$ : Fiocruz.

(Org.) (2000b) A loucura da história. RJ: LAPS/ENSP/FIOCRUZ.

CASTEL, R. (1978) A ordem psiquiátrica: a idade de ouro do alienismo. RJ: Graal.

COSTA-RosA, A. (1987) Saúde mental comunitária: análise dialética de um movimento alternativo. Dissertação de Mestrado. Instituto de Psicologia. USP. SP. 
, (1995) Práticas de cura nas religiões e tratamento psíquico em Saúde Coletiva. Tese de Doutorado. Instituto de Psicologia. USP. SP.

, (1999) Modo Psicossocial: um novo paradigma nos tratamentos psíquicos na Saúde Coletiva. Revista Vertentes, nº. 5, p. 11- 22.

, (2000) O Modo Psicossocial: um paradigma das práticas substitutivas ao modo asilar. In: AMARANTE, P.D.C. (Org.) Ensaios de Loucura \& Civilização. RJ: Fiocruz, vol. 1, p. 141-168.

, (2002) A Instituição de Saúde Mental como dispositivo de produção de subjetividade. UNESP, Assis, SP. (mimeo).

FOUCAULT, M. (1982) A Vontade de Saber (História da Sexualidade I) $4^{\mathrm{a}} \mathrm{ed.,}$ (Albuquerque, M. T. C., Trad.) Rio de Janeiro: Graal.

, (1984) A verdade e as formas jurídicas, "Cadernos da PUC/RJ", série Letras e Artes, 6/74, n 16

, (1999a) História da Loucura na Idade Clássica. $6^{a}$ edição. São Paulo: Perspectiva. (Original publicado em 1972).
, (1999b) Vigiar e punir: nascimento da prisão. (Ramalhete, R., Trad.) $21^{\mathrm{a}}$ ed. Petrópolis: Vozes. 288 p. (Original publicado em 1975).

, (1999c) Microfísica do poder. (Machado, R. Org. e Trad.) 14a ed. Rio de Janeiro: Graal.

GOFFMAN, E. (1987) Manicômios, prisões e conventos. SP: Perspectiva.

JORGE, M. A. C. (1983) Discurso médico e discurso psicanalítico. In: CLAVREUL, J. A ordem médica: podere impotência do discurso médico. (Noujaim, J.G. et al.; Trad.) SP: Brasiliense.

NICÁCIO, F. (1994) O processo de transformação da Saúde Mental em Santos: desconstrução de saberes, instituições e cultura. Dissertação de Mestrado, PUC - SP.

ROTELLI, F. et al. (1990) Desinstitucionalização. SP: Hucitec.

YASUI, S. (1999) A construção da reforma psiquiátrica e seu contexto histórico. Dissertação de Mestrado. UNESP - Assis, SP.

Recebido para publicação em 2 de outubro de 2002 e aceito em 11 de março de 2003. 
